ISSN 1112-9867

\title{
ASSESSMENT ON AIR QUALITY PATTERN: A CASE STUDY IN PUTRAJAYA, MALAYSIA
}

\author{
A. Kamaruzzaman ${ }^{1}$, A. S. M. Saudi ${ }^{1, *}$, A. Azid ${ }^{2}$, A. Balakrishnan ${ }^{1}$, I. F. Abu ${ }^{1}$, N. A. Amin ${ }^{1}$ \\ and Z. I. Rizman ${ }^{3}$ \\ ${ }^{1}$ Department of Environmental Healthcare, Institute of Medical Science and Technology, \\ Universiti Kuala Lumpur, 43600 Kajang, Selangor, Malaysia \\ ${ }^{2}$ Faculty of Bioresources and Food Industry, Universiti Sultan ZainalAbidin, 22200 Besut, \\ Terengganu, Malaysia \\ ${ }^{3}$ Faculty of Electrical Engineering, UniversitiTeknologi MARA, 23000 Dungun, Terengganu, \\ Malaysia
}

Published online: 05 October 2017

\begin{abstract}
Nowadays, air quality problem has become a major issue in Malaysia for the past two decades. This study aims to determine the pattern of the air quality status, investigate the significant pollutant, relationship between air pollutants and API and evaluate the pattern of air pollution. Data from Putrajaya monitoring station based on three years observation (2011-2013) were used. Multivariate techniques such as principal component analysis (PCA), factor analysis (FA) and statistical process control (SPC). The method of PCA and FA has identified that five parameters with the value $>0.75$ affected the quality of air. SPC shows that $\mathrm{SO}_{2}$ pollutants had influence the quality of air the most compared to other pollutants. From the study, it can be stipulated that the chemometric technique can provide meaningful information on the spatial variability of large and complex air quality data.
\end{abstract}

Author Correspondence: ahmadshakir@unikl.edu.my

doi: http://dx.doi.org/10.4314/jfas.v9i4s.44 
Keywords: air quality pattern; PCA; FA; SPC.

\section{INTRODUCTION}

\subsection{Background}

Nowadays, air quality problem has become a major issue in Malaysia for the past two decades. Rapid urbanization and industrialization parallel the worsening air quality in certain areas. Air pollution can be defined as contamination of the indoor or outdoor environment by biological, chemical or physical agents which changes the natural features of the atmosphere [1]. In Malaysia, mobile sources are the major source of air pollution, followed by stationary sources and trans-boundary sources. A densely populated urban area is a highly potential area and a very prone zone to experience the air-quality problems. The exposure to air pollutants can give serious effects on human health, animals and vegetation, buildings and global environment [2].

The Putrajaya is one of the main economic zones in Malaysia. The rapid transformation of the area into a wide urban region during the last decades of the 20th century has contributed too many of the environmental issues, particularly air pollution. For the past five years, the three major sources of air pollution in Malaysia are mobile sources (70-75\% of total air pollution), stationary sources (20-25\%) and open burning (3-5\%) [3]. Besides, other sources of pollutants such as dust and fine particulate which contributed to the development of haze in the Klang Valley were contributed by the inefficiency of diesel-powered vehicles and the smoke aerosol from fires on Peninsular Malaysia [4]. The exposure to air pollution may adversely affect human health.

In Malaysia, air pollution had been constantly an overwhelming issue for legislators, aviation industry and the citizens. It is constantly making headlines in major newspapers and subsequently heightens the anxiety of the citizens, particularly during the haze episode. The worst episode of agricultural and open burning in Malaysia was reported in Sepang and Kuala Selangor in 2002 which 500 hectares of agricultural waste involved, thus led to an unhealthy level of API in the Klang Valley [5].

Previous reports had shown that there are strong associations between outdoor air pollution exposure and Ischemic Heart Disease (IHD), stroke, Chronic Obstructive Pulmonary Disease 
(COPD), Acute Lower Respiratory Infections (ALRI) and lung cancer [6].

\subsection{Chemometric Techniques}

Chemometric techniques (also known as multivariate techniques) are a better tool and better understanding for analyzing air quality data. Chemometric in the environmental field is verified to be a functional tool to identify the sources of pollution [7-8]. The analysis is the most suitable tool for the reduction and interpretation of the data [7].

There are few studies in Malaysia using chemometric techniques such as principal component analysis (PCA), factor analysis (FA) and statistical process control (SPC). PCA is a method of creating new variables which are linear composites of the original variables to identify the sources of pollutant [8]. Besides, FA is usually applied following the PCA method [7]. It presents the most significant variables details due to spatial and temporal variations by putting them from the less significant variables with minimum loss of the original information [8]. SPC is a statistical analysis that commonly used for quality control techniques in an organization or a process. Therefore, the application of chemometric techniques was suggested for the effective air quality management in Malaysia [8].

\section{EXPERIMENTAL}

\subsection{Study Design}

The study conducted is an analytical study design, which based on statistical principles to analyze a set of database on air quality parameters. This study is designed to analyze the pattern of the air quality in Putrajaya, Wilayah Persekutuan, Malaysia.

\subsection{Study Area}

The sampling station used in this study is namely as Putrajaya air monitoring station (latitude: $3^{\circ} 00^{\prime} 44^{\prime \prime} \mathrm{N}$; longitude: $101^{\circ} 68^{\prime} 59^{\prime \prime}$ E) (Fig. 1). The air monitoring stations are managed by the Air Quality Division of the Department of Environment (DOE) under the Ministry of Natural Resource and Environment, Malaysia. Putrajaya air monitoring station was located at SekolahKebangsaanPutrajaya 8(2), Jalan P8/E2, Presint 8, which surrounded by residential area and major road. This area is selected to give a general representation of the air quality level in Putrajaya, Malaysia. 


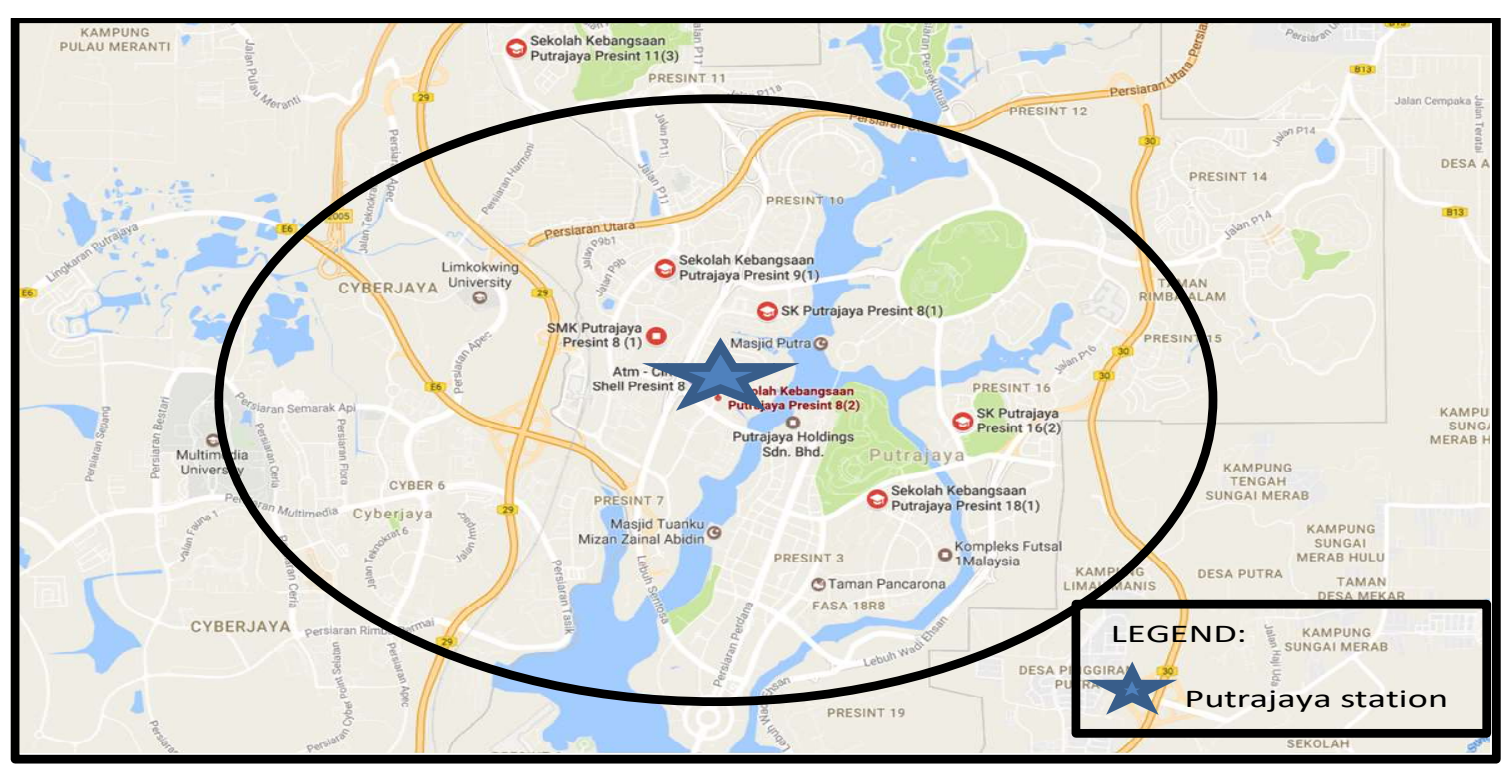

Fig.1. Putrajaya map within 5km radius of Putrajaya monitoring station

\subsection{Data Collection}

Secondary air quality data was obtained from the Air Quality Division of the Department of Environment (DOE) under the Ministry of Natural Resource and Environment, Malaysia. The data was collected and monitored by AlamSekitar Malaysia Sdn. Bhd. (ASMA) which is one of the authorized agencies.

A three-year databases (2011-2013) were used in this study and it contains five major air pollutants include carbon monoxide $(\mathrm{CO})$, nitrogen dioxide $\left(\mathrm{NO}_{2}\right)$, sulphur dioxide $\left(\mathrm{SO}_{2}\right)$, ozone $\left(\mathrm{O}_{3}\right)$ and particulate matter with diameter less than 10 microns $\left(\mathrm{PM}_{10}\right)$ as well as meteorological variables such as wind speed, wind direction, ambient temperature and humidity. The measurement for these variables is recorded hourly. In addition, Air Pollutant Index (API) values were also used in this study.

A total of 263,050 hourly data sets $(2,6305$ observations x 10 parameters) were used in this study. There is several number of missing data from the overall data sets. Therefore, the nearest neighbour method was applied to predict the unknown values using the known values at the neighbour locations where sample points are missing $[8,12]$. The data was computed by using XLSTAT 2017 software.

\subsection{Principal Component Analysis (PCA)}

Principal component analysis (PCA) is a technique used to emphasize variation and bring out strong patterns in a dataset. It is often used to make data easy to explore and visualize. In this 
study, interrelated variable was interpreted by PCA to identify the sources of air emission in Putrajaya, Wilayah Persekutuan, Malaysia. This can be done as this method would show the most significant parameters and omit the less significant parameters without losing the original variables. PCA was calculated as in equation below:

$z_{i j}=a_{i 1} x_{1 j}+a_{i 2} x_{2 j}+a_{i 3} x_{3 j}+\ldots . . .+a_{i m} x_{m j}$

where ' $z$ ' is component score,' $\alpha$ ' is component loading, ' $x$ ' is the measured value of variables, ' $\mathrm{i}$ ' is the component number, ' $\mathrm{j}$ ' is the sample number and ' $\mathrm{m}$ ' is the total number of variables.

\subsection{Factor Analysis (FA)}

FA is usually carried out after PCA has been successfully applied to identify the different possible sources of pollution base on the activities in the air quality monitoring environment [7]. It also helps to reduce the least significant variables in the dataset to simplify the data structure in the PCA [16]. Varimax rotation is only applied to the PCs with eigenvalues equal to or more than 1 , which considered significant to obtain the new variables called as varimax factors (VFs) or factor loadings [12].

In addition, the VFs coefficient with a correlation from 0.75 are considered as strong significant factor loading, those that range from $0.50-0.74$ have moderate while of $0.30-0.49$ are classified as weak significant factor loading. FA was calculated as in equation below:

$z_{i j}=a_{f 1} x_{1 i}+a_{f 2} x_{2 i}+a_{f 3} x_{3 i}+\ldots . . .+a_{f m} f_{m i}+e_{f i}$

where ' $z$ ' is the measured value of a variable, ' $a$ ' is the factor loading, ' $f$ is the factor score, ' $e$ ' is the residual term accounting for errors or other sources of variation, ' $i$ ' is the sample number, ' $\mathrm{j}$ ' is the variable number and ' $\mathrm{m}$ ' is the total number of factors.

\subsection{Statistical Process Control (SPC)}

In this study, SPC is applied to evaluate pattern of the significant air pollutants that influence air quality in Putrajaya, Wilayah Persekutuan, Malaysia within three years database time (2011-2013). From the control chart, a straight line connected the successive points which demonstrating the characteristic level of an air pollutant in time. Moreover, there were there straight lines that indicating the upper control limit (UCL), the control limit (CL) and the lower control limit (LCL). These control limits were compared to the national air quality standard limit. 


\section{RESULTS AND DISCUSSION}

\subsection{Descriptive Statistic of Hourly Average Air Quality and Air Pollution Index}

Table 1 shows the descriptive analysis of hourly average air quality concentration of $\mathrm{SO}_{2}$, $\mathrm{NO}_{2}, \mathrm{O}_{3}, \mathrm{CO}, \mathrm{PM}_{10}$ and API value for the period 2011-2013. It shown that concentration of $\mathrm{SO}_{2}, \mathrm{NO}_{2}$, and $\mathrm{CO}$ did not exceed the permitted level of RMAQG which is $0.13 \mathrm{ppm}, 0.17 \mathrm{ppm}$ and $30.00 \mathrm{ppm}$ over three years period.

However, Putrajaya had been exposed to the maximum concentration of $\mathrm{O}_{3}$ and $\mathrm{PM}_{10}$ which exceed the reading of the RMAQG (Table 1). The maximum value of $\mathrm{O}_{3}$ was $0.12 \mathrm{ppm}$ which higher compared to the level of RMAQG, $0.10 \mathrm{ppm}$. The highest maximum value of $\mathrm{PM}_{10}$ concentration was $592 \mu \mathrm{g} / \mathrm{m}^{3}$, which was higher than the RMAQG permitted level of $150 \mu \mathrm{g} / \mathrm{m}^{3}$. This value was high but did not exceed the hazardous level of $\mathrm{PM}_{10}$ that is $600 \mu \mathrm{g} / \mathrm{m}^{3}$.

Table 1. Descriptive statistic of hourly average air quality and air pollution index in Putrajaya, 2011-2013

\begin{tabular}{ccccccc}
\hline & \multicolumn{5}{c}{ Parameters } \\
Statistic & $\mathbf{S O}_{2}$ & $\mathbf{N O}_{2}$ & $\mathbf{O}_{\mathbf{3}}$ & $\mathbf{C O}$ & $\mathbf{P M}_{\mathbf{1 0}}$ & $\mathbf{A P I}$ \\
& $(\mathbf{p p m})$ & $(\mathbf{p p m})$ & $\mathbf{( p p m )}$ & $\mathbf{( \mathbf { p p m } )}$ & $\left(\boldsymbol{\mu g} / \mathbf{m}^{\mathbf{3}}\right)$ & \\
\hline Min & 0.00 & 0.00 & 0.00 & 0.00 & 5.00 & 8.00 \\
Max & 0.10 & 0.07 & $\mathbf{0 . 1 2}$ & 7.26 & $\mathbf{5 9 2 . 0 0}$ & $\mathbf{1 9 9 . 0 0}$ \\
Mean & 0.00 & 0.02 & 0.03 & 0.77 & 48.51 & 45.65 \\
SD & 0.01 & 0.01 & 0.02 & 0.47 & 28.97 & 17.87 \\
Averaging & $1 \mathrm{hr}$ & $1 \mathrm{hr}$ & $1 \mathrm{hr}$ & $1 \mathrm{hr}$ & $24 \mathrm{hrs}$ & \\
time & & & & & & \\
RMAQG & 0.13 & 0.17 & 0.10 & 30.00 & 150.00 & \\
\hline
\end{tabular}

Note: Min $=$ Minimum, Max $=$ Maximum, $\mathrm{SD}=$ Standard deviation, RMAQG $=$ Recommended Malaysia Air Quality Guidelines

Moreover, the average mean of API was 45.65 shows that it will be categorized under good API status without any effect on human health. However, the maximum value of API was 199 which indicate that the air status in unhealthy condition with mild aggravation of symptoms among high risks group such as those with heart or lung diseases. The maximum value of API 
increased was probably reflected from the $\mathrm{PM}_{10}$ maximum reading as proven that $\mathrm{PM}_{10}$ give high impact on API value [9].

\subsection{Identification of Major Possible Sources of Pollutants}

PCA together with FA was performed on the data sets (Ws, Wd, Humidity, $\mathrm{SO}_{2}, \mathrm{NO}_{2}, \mathrm{O}_{3}, \mathrm{CO}$ and $\mathrm{PM}_{10}$ ) for three consecutive years 2011 to 2013 to examine the parameters as well as to identify the major possible sources of variation at Putrajaya, Wilayah Persekutuan, Malaysia. Four PCs were obtained with the eigenvalue greater than $0.75(>0.75)$ which account for more than $23 \%, 46 \%, 58 \%$ and $79 \%$ respectively of the total variance in the data set as shown in the PCA loading plot in Fig.2. Four varifactors (VFs) were obtained through the FA performed on the PCs. Only factor loadingsare greater than 0.70 were interpreted. The result of FA is presented in Table 2 as well as factor loadings, eigenvalues, the total variance and cumulative percentages.

Table 2. The factor loadings after varimax rotation (PCA)

\begin{tabular}{ccccc}
\hline Variables & VF1 & VF2 & VF3 & VF4 \\
\hline $\mathrm{Ws}$ & 0.203 & $\mathbf{0 . 8 2 8}$ & 0.055 & -0.213 \\
$\mathrm{Wd}$ & -0.132 & $\mathbf{0 . 8 2 8}$ & 0.044 & 0.017 \\
Humidity & -0.269 & -0.708 & -0.127 & 0.214 \\
$\mathrm{SO}_{2}$ & 0.075 & 0.074 & $\mathbf{0 . 9 8 8}$ & 0.064 \\
$\mathrm{NO}_{2}$ & 0.162 & -0.056 & 0.083 & $\mathbf{0 . 9 0 6}$ \\
$\mathrm{O}_{3}$ & 0.704 & 0.447 & -0.011 & 0.143 \\
$\mathrm{CO}$ & 0.261 & -0.170 & 0.014 & $\mathbf{0 . 8 6 2}$ \\
$\mathrm{PM}_{10}$ & 0.732 & -0.046 & 0.134 & 0.443 \\
Eigenvalue & 2.953 & 2.471 & 0.948 & 0.757 \\
Variability (\%) & 23.083 & 23.505 & 11.418 & 21.202 \\
Cumulative (\%) & 23.083 & 46.588 & 58.006 & 79.208 \\
\hline
\end{tabular}

The second varimax factor (VF2) accounts for $23.08 \%$ of the total variance which indicate a strong positive loading for wind speed (0.828), wind direction (0.828). The transportation of both primary and secondary pollutants from point source to non-point source are by wind speed [10-11].

Meanwhile, the third varimax factor (VF3) accounts for $11.42 \%$ of the total variance which 
shows a strong positive loading for $\mathrm{SO}_{2}(0.988)$. The sources of $\mathrm{SO}_{2}$ is resulted from the motor vehicles combustions, coal powered power plants and uncontrolled burning of forests, volcano activities and dust storm from neighbouring country due to various activities [7].

For the fourth varimax factor (VF4) records $21.2 \%$ of the total variance with a strong positive loading for $\mathrm{NO}_{2}(0.906)$ and $\mathrm{CO}(0.862)$. The spatial variation in the source of $\mathrm{CO}$ is from engine boats and motor vehicles, especially when the engines are not turned properly which causes incomplete combustion [12]. $\mathrm{NO}_{2}$ is largely due to the industrial activities as well as the heavy traffic congestion. An analysis on $\mathrm{NO}_{2}$ emission in Malaysia proves that power stations and industrial activities released about $69 \%$ of this pollutant to the air, while $28 \%$ is from motor vehicles and the remaining 3\% is from other sources [13]. Besides, a study state that there are two condition that produce $\mathrm{NO}_{2}$ in the air as when the nitrogen in the fuel is burnt also when the nitrogen at the very high temperature and oxygen react in the air [14].
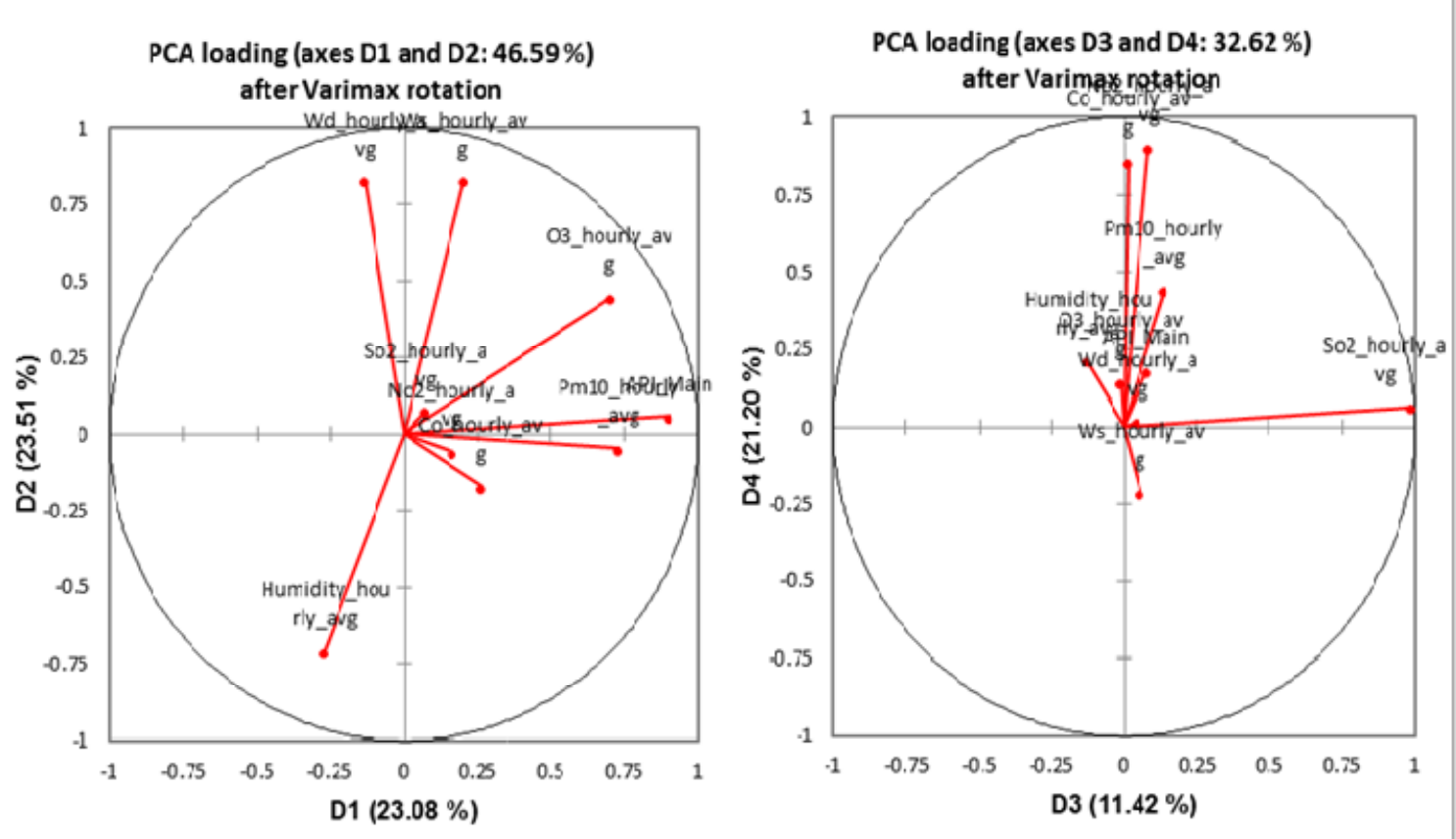

Fig.2. Plot diagram for PCA loading after varimax rotation

\subsection{Coefficient of Correlation (Spearman)}

Spearmen's correlation test was used to determine the correlation between the air pollutants parameter and Air Pollution Index (API). Thus, in this study, the coefficient correlation (r) is determined by the range of $0-0.49$ (low correlation), 0.5-0.69 (moderate correlation) and 0.7-1.0 (high correlation). Only high correlation coefficient value was interpreted in this study. 
The result of coefficient correlation in the study area from 2011-2013 can be seen in Table 3 . From Table 3, $\mathrm{NO}_{2}$ and $\mathrm{CO}$ shows high correlation with the coefficient correlation value of $\mathrm{r}$ $=0.729$. The result illustrated that the dispersion of $\mathrm{NO}_{2}$ from the industrial activities in the study area (Putrajaya) which also affected by other factor including the CO released from engine boats and motor vehicles, especially when the engines turned on, thus leads to the incomplete combustion [15].

Next, the coefficient correlation between API and $\mathrm{PM}_{10}$ shows high correlation value, which $\mathrm{r}=0.701$. This indicates that the concentration of $\mathrm{PM}_{10}$ dispersed in the air proven to give high impact on the API as compared to other pollutants [9].

Table 3. Result of coefficient correlation in study area from 2011-2013

\begin{tabular}{ccccccc}
\hline Variables & $\mathbf{S O}_{\mathbf{2}}$ & $\mathbf{N O}_{\mathbf{2}}$ & $\mathbf{O}_{\mathbf{3}}$ & $\mathbf{C O}$ & $\mathbf{P M}_{\mathbf{1 0}}$ & $\mathbf{A P I}$ \\
\hline $\mathrm{SO}_{2}$ & $\mathbf{1}$ & 0.142 & 0.129 & 0.080 & 0.182 & 0.160 \\
$\mathrm{NO}_{2}$ & 0.142 & $\mathbf{1}$ & 0.240 & $\mathbf{0 . 7 2 9}$ & 0.475 & 0.315 \\
$\mathrm{O}_{3}$ & 0.129 & 0.240 & $\mathbf{1}$ & 0.215 & 0.406 & 0.617 \\
$\mathrm{CO}$ & 0.080 & $\mathbf{0 . 7 2 9}$ & 0.215 & $\mathbf{1}$ & 0.549 & 0.360 \\
$\mathrm{PM}_{10}$ & 0.182 & 0.475 & 0.406 & 0.549 & $\mathbf{1}$ & $\mathbf{0 . 7 0 1}$ \\
$\mathrm{API}$ & 0.160 & 0.315 & 0.617 & 0.360 & $\mathbf{0 . 7 0 1}$ & $\mathbf{1}$ \\
\hline
\end{tabular}

\subsection{Pattern of the Major Air Pollutants and Air Pollution Index in Putrajaya, Malaysia}

The pattern of air pollutant $\left(\mathrm{SO}_{2}\right)$ and API were computed via time series analysis by using SPC. A control chart for the $\mathrm{SO}_{2}$ parameters was derived to monitor the concentration of the air pollutants and to identify the value that exceeding the permitted limits value.

Fig.3 shows the finding of control chart in the monitoring the pattern of $\mathrm{SO}_{2}$ at Putrajaya (2011-2013). The control limit (CL) value for $\mathrm{SO}_{2}$ was $0.004 \mathrm{ppm}$, upper control limit (UCL) was $0.006 \mathrm{ppm}$ and lower control limit (LCL) was $0.002 \mathrm{ppm}$. The highest value of $\mathrm{SO}_{2}$ was $0.11 \mathrm{ppm}$ on $24^{\text {th }}$ December 2011 which resulted from the motor vehicles combustions, coal powered power plants and uncontrolled burning of forests, volcano activities and dust storm from neighbouring country due to various activities [7]. 


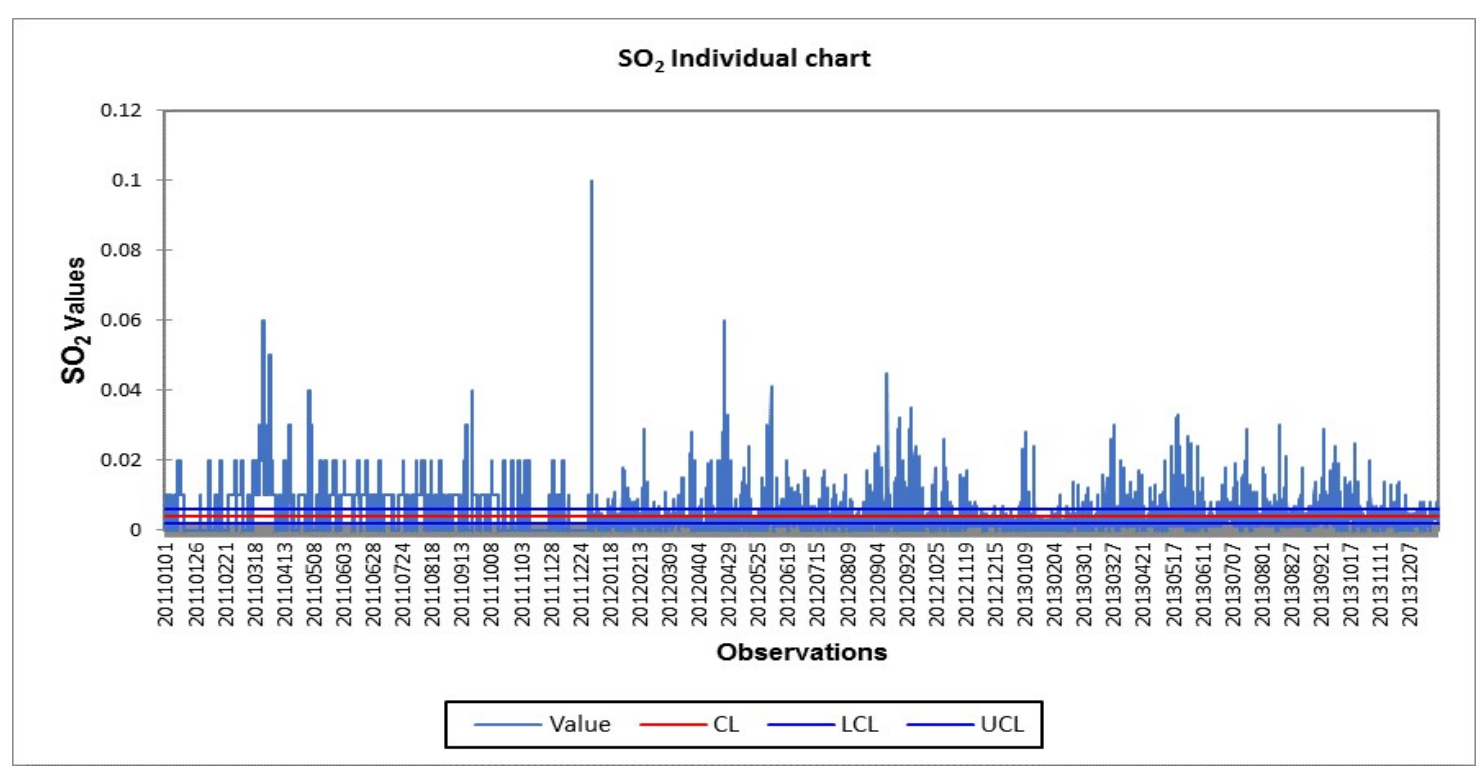

Fig.3. Control chart of $\mathrm{SO}_{2}$ for Putrajaya (2011-2013)

\section{CONCLUSION}

In this study, multivariate statistic and chemometric techniques were used to identify the spatial variation of air quality in selected monitoring stations in Putrajaya, Wilayah Persekutuan, Malaysia. The descriptive analysis was used to describe the analysis of hourly average air quality concentration of major air pollutant value such as $\mathrm{SO}_{2}, \mathrm{NO}_{2}, \mathrm{O}_{3}, \mathrm{CO}, \mathrm{PM}_{10}$ and API for the period of 2011-2013. PCA together with FA indicates that only five parameters with strong positive loadings $>0.75$ which is $\mathrm{Ws}, \mathrm{Wd}, \mathrm{SO}_{2}, \mathrm{NO}_{2}$ and $\mathrm{CO}$ that have strong variation. The major contribution sources to these pollutants are from anthropogenically induced emission (automobiles, industries, power plants, transboundary sources and construction sites). The pattern of air pollutant $\left(\mathrm{SO}_{2}\right)$, which had influence the quality of air the most and were computed by using time series analysis by using SPC [17-18].

\section{ACKNOWLEDGEMENTS}

The authors are grateful to the Department of Environment (DOE) for the supply of data required for the completion of this study. 


\section{REFERENCES}

[1] World Health Organization (WHO). Ambient air pollution: A global assessment of exposure and burden of disease. Geneva: WHO, 2016

[2]Azmi S Z, Latif M T, Ismail A S, Juneng L, Jemain A A. Trend and status of air quality at three different monitoring stations in the Klang Valley, Malaysia. Air Quality, Atmosphere and Health, 2010, 3(1):53-64

[3] Afroz R, Hassan M N, Ibrahim N A. Review of air pollution and health impacts in Malaysia. Environmental Research, 2003, 92(2):71-77

[4] Keywood M D, Varutbangkul V, Bahreini R, Flagan R C, Seinfeld J H. Secondary organic aerosol formation from the ozonolysis of cycloalkenes and related compounds.Environmental Science and Technology, 2004, 38(15):4157-4164

[5] Mahmud M. Active fire and hotspot emissions in Peninsular Malaysia during 2002 burning season. Malaysian Journal of Society and Space, 2005, 1(1):32-45

[6] World Health Organization (WHO). 7 million premature deaths annually linked to air pollution. Geneva: WHO, 2014

[7] Mutalib S N S A, Juahir H, Azid A, Sharif S M, Latif M T, Aris A Z, Zain S M, Dominick D. Spatial and temporal air quality pattern recognition using environmetric techniques: A case study in Malaysia.Environmental Science: Processes and Impacts, 2013, 15(9):1717-1728

[8] Azid A, Juahir H, Amran MA, Suhaili Z, Osman MR, Muhamad A, Abidin IZ, Sulaiman NH, Saudi AS.Spatial air quality modelling using chemometrics techniques: A case study in Peninsular Malaysia. Malaysian Journal of Analytical Sciences, 2015, 19(6):1415-1430

[9] Amran MA, Azid A, Juahir H, Toriman ME, Mustafa AD, Hasnam CN, Azaman F, Kamarudin MK, Saudi AS, Yunus K. Spatial analysis of the certain air pollutants using environmetric techniques. JurnalTeknologi, 2015, 75(1):241-249

[10] Dawson JP, Adams PJ, Pandis SN. Sensitivity of PM2.5 to climate in the Eastern U.S: A modeling case study. Atmospheric Chemistry and Physics, 2007, 7(16):4295-4309

[11] Kleeman M J. A preliminary assessment of the sensitivity of air quality in California to global change. Climatic Change, 2007, 87(1):273-292

[12] AhmadIsiyaka H, Juahir H, Toriman ME, Gasim BM, Azid A, Amri MK, Ibrahim A, Usman UN, Rano AR, Garba MA. Spatial assessment of air pollution index using 
environmetric modeling techniques. Advances in Environmental Biology, 2014, $8(24): 244-256$

[13] Department of Environment (DOE) Malaysia. A guide to air pollutant index (API) in Malaysia. Putrajaya: Ministry of Natural Resources and Environment,2009

[14] Brunekreef B, Holgate ST. Air pollution and health. Lancet, 2002, 360(9341):1233-1242

[15] Janssen NA, van Vliet PH, Aarts F, Harssema H, Brunekreef B. Assessment of exposure to traffic-related air pollution of children attending school near motorways. Atmospheric Environment, 2001, 35(22):3875-3884

[16] Deepulal P M,Gireesh Kumar T R, Sujatha C H. Behaviour of REEs in a tropical estuary and adjacent continental shelf of southwest coast of India: Evidence from anomalies.Journal of Earth System Science, 2012,121(5):1215-1227

[17] Kamarudin M K, Nalado A M, Kasmuri A, Toriman M E, Juahir H, Umar R, Jamil N R, Saudi A S, Rizman Z I, Gasim M B, Hassan A R. Assessment of river plan changes in Terengganu River using RS and GIS method. Journal of Fundamental and Applied Sciences, $2017,9(2 S): 28-45$

[18] Saudi A S, Kamarudin M K, Ridzuan I S, Ishak R, Azid A, Rizman Z I. Flood risk index pattern assessment: Case study in Langat river basin. Journal of Fundamental and Applied Sciences, 2017, 9(2S):12-27

\section{How to cite this article:}

Kamaruzzaman A, Saudi A S M, Azid A, Balakrishnan A, Abu I F, Amin N A, Rizman Z I. Assessment on air quality pattern: a case study in putrajaya, malaysia. J. Fundam. Appl. Sci., 2017, 9(4S), 789-800. 